\title{
The effect of acute rhinosinusitis on pulmonary function in adults
}

\author{
*Jens Georg Hansen ${ }^{a}$ \\ associate Professor, Specialist in General Medicine, Aalborg Hospital, Aarhus University Hospital, Denmark
}

Received 30th November 2007; revised version received 9th June 2008; accepted 3rd November 2008; online 22nd January 2009

\begin{abstract}
Objective: To evaluate the influence of acute rhinosinusitis on lung function as measured by spirometry.

Method: An observational study in Danish general practice on 25 adult patients with a clinical diagnosis of acute rhinosinusitis and without any signs of chronic lung disease or allergy. Patients performed spirometry at the initial acute visit and then eight weeks later when the rhinosinusitis had resolved.

Results: Eight weeks after the initial visit there was a significant increase in the maximum mid-expiratory flow $\left(F_{25-75}\right)$, and in peak flow. Conclusion: Acute rhinosinusitis in adults without any sign of chronic lung disease or allergy is accompanied by a temporary reduction in maximum mid-expiratory flow and peak flow. This may be caused by subclinical inflammation in the airways during acute rhinosinusitis. Further studies with extended lung function measurements are needed to evaluate and confirm this finding.

(c) 2009 General Practice Airways Group. All rights reserved.

JG Hansen. Prim Care Resp J 2009; 18(3): 224-225.

doi:10.3132/pcrj.2009.00005
\end{abstract}

Keywords acute rhinosinusitis, spirometry, lung function, C-reactive protein, general practice.

\section{Introduction}

In general practice, acute rhinosinusitis is a frequent diagnosis based mainly on symptomatology without radiology, and defined as a sudden onset of two or more of the following symptoms: blockage/congestion; nasal discharge; facial pain/pressure; and reduction or loss of smell for $<12$ weeks. ${ }^{1}$

Uncertainty about the diagnosis is a problem; i.e. is the patient presenting a purulent acute rhinosinusitis or a prolonged common cold? One study evaluated symptoms and signs in patients suspected of having acute maxillary sinusitis (defined as purulent or mucopurulent antral aspirate) and found that elevation in both C-reactive protein (CRP) and erythrocyte sedimentation rate (ESR) were useful diagnostic criteria for acute maxillary sinusitis. ${ }^{2}$ Chronic obstructive pulmonary disease (COPD) has a high frequency of nasal symptoms and abnormalities in the paranasal sinuses on CT scanning. ${ }^{3}$ A frequent sequela in patients with existing asthma is a worsening of lower airways disease with acute or chronic sinusitis. ${ }^{4-7}$ However, the influence of acute rhinosinusitis on lower airway function in patients without chronic airway diseases or allergy has not been identified in the literature (see www.pubmed.gov).

Therefore, the aim of this study was to investigate the effect of acute rhinosinusitis on pulmonary function in adult patients without chronic lung diseases or allergy.

\section{Methods}

The study took place from 1 January to 30 December 2005 in a general practice with two physicians. Patients aged 18 years and above were included consecutively, but only once, if they had an acute infection of the upper airways such as acute rhinosinusitis, presenting with facial pain, anterior discharge and a CRP value $>10 \mathrm{mg} / \mathrm{l}$ (normal $<8 \mathrm{mg} /$ ). Exclusion criteria were: recurrent acute rhinosinusitis; a diagnosis of asthma, COPD, allergy, or any condition or chronic disease that could modify the levels of CRP; pregnancy; duration of symptoms for more than four weeks; and unwillingness to participate. The exclusion criteria were based on interview and access to the patient's medical record. None of the patients showed any symptoms (such as change in cough,

\footnotetext{
*Corresponding author: Associate Professor Jens Georg Hansen, Aalborg Hospital, Aarhus University Hospital, Lindenborgvej 93 st. tv., DK - 9200 Aalborg SV, Denmark. Tel: +4598165865 Fax: +4598187501 E-mail: jensgeorg@dadlnet.dk
} 
sputum or dyspnoea) or signs (as confirmed by a detailed clinical examination) of lower respiratory tract infection. Patients were asked to return for a repeat visit eight weeks later, and were allowed to use weak analgesics e.g. paracetamol and local decongestives. Antibiotics were prescribed dependent on the severity of the clinical symptoms. No other medical treatment was allowed during the study.

\section{Sample size}

We wanted to be $80 \%$ sure of rejecting (on a $5 \%$ level) the hypothesis that the lung function variables were the same at visit 1 and visit 2 . The required number of patients was approximately 25 .

\section{Clinical evaluation}

The patient's age, sex, smoking habits (calculated as packyears), symptom duration (calculated as days with facial pain), and the initial pain score were recorded. The scoring system ranged from $0-5$, with 5 indicating the most severe pain. This scoring system has been used in other studies and has been found to be useful in diagnosing acute rhinosinusitis and in determining whether or not to treat with antibiotics. ${ }^{8,9}$ One blood sample was taken to estimate the concentration of CRP (Nycocard CRP single test, Axis-Shield-PCO A/S, Norway). The analysis was performed in the clinic and the result was available within five minutes. After careful instruction by the nurse, pulmonary function testing was carried out with a computerised spirometer (Vitalograph PFT II printer). The best of three reproducible and correct time/volume curves was used as the patient's result. The following parameters were measured and corrected for BTPS (Body Temperature, Pressure, Saturations): forced vital capacity (FVC); forced expiratory volume during the first second (FEV1); maximum mid-expiratory flow from $25-75 \%$ of FVC (F25-75); and peak expiratory flow (PEF). Spirometry was performed according to ERS criteria. ${ }^{10}$ Normal values were derived from the Danish Society of Respiratory Medicine. ${ }^{11}$

\section{Evaluation of outcome}

Patients were asked to record how many days they had facial pain after the initial visit. At the final visit the pain score and
CRP were recorded, and spirometry was repeated.

\section{Ethics approval}

The Regional Scientific Ethics Committee accepted the investigation. Written informed consent was obtained from all participants.

\section{Data analysis}

The computer program Statistix 4.0 conducted data analysis. The Wilk-Shapiro test was used to examine whether the lung function variables conformed to a normal distribution, and paired T-test was used to test whether the mean of the differences of measured patients was different from zero. Correlations were tested with Pearsons test and calculated as correlation coefficients $(r)$. The significance level was set to $5 \%$.

\section{Results}

Twenty-five patients were included in the study. Median age was 40 years (quartiles 29-50), 80\% were women, and $20 \%$ were current smokers with a mean smoking history of 8.8 pack-years.

The median duration of pain before entering the study was six days (quartiles 5-8), and the median duration of pain after entering the study was seven days (quartiles 6-14). The median pain intensity before entering the study was 4 (quartiles 3-4). At the final visit, eight weeks after entering the study, all patients had recovered completely and none had facial pain.

At the initial visit the median value of CRP was $20 \mathrm{mg} / \mathrm{l}$ (quartiles 15-23) and at follow-up all had achieved normal values of $\mathrm{CRP}(<8 \mathrm{mg} / \mathrm{l})$. The variables FEV $1, F V C, F_{25-75}$, and PEF, with the Wilk-Shapiro test, showed a normal distribution. Table 1 shows the results of the main spriometry values. F25-75 and PEF improved significantly between the initial and final visit, whereas no changes were seen in FEV 1 and FVC. There was a significant correlation between CRP and $F_{25-75}(r=0.65$, $p<0.05)$, but not with PEF $(r=0.29)$. There was also a significant correlation between changes in $\mathrm{F}_{25-75}$ and PEF $(r=0.75, p<0.05)$, whereas no correlation was found between pain score and $\mathrm{F}_{25-75}(\mathrm{r}=0.16)$ or PEF $(r=-0.08)$. Antibiotics

Table 1. Differences in pulmonary function variables (median values in litres) between initial (first) and final (second) visit. $95 \%$ confidence intervals given in brackets.

\begin{tabular}{lccc} 
Variables & First visit & Second visit & P value-value\# \\
\hline FEV 1 & $3.4(2.9-3.6)$ & $3.4(3.1-3.7)$ & NS \\
FVC & $4.2(3.8-4.5)$ & $4.3(3.8-4.6)$ & NS \\
FEV 1 /FVC & $81(77-83)$ & $82(77-84)$ & NS \\
F $25-75$ & $3.1(2.7-3.7)$ & $3.6(3.0-4.1)$ & 0.009 \\
\hline PEF & $413(363-471)$ & $485(410-526)$ & 0.03 \\
\hline Ns= non significance & &
\end{tabular}


were prescribed to a minority of the patients and did not influence the results.

\section{Discussion}

This study shows that, in patients suffering from acute rhinosinusitis with no past history of allergy, hay fever, asthma, COPD or recurrent acute rhinosinusitis, the acute episode was associated with a temporary but significant reduction in lung function. This observation has not been published before (see www.pubmed.gov). The reduction was only found in $\mathrm{F}_{25-75}$ and in PEF, whereas no significant changes were observed in $\mathrm{FEV}_{1}$ and FVC.

A possible explanation might be small airway obstruction and air trapping. However, we did not expect this finding and did not test if any slight obstruction in the small airways was reversible to inhaled bronchodilators. This finding of subclinical airways obstruction should be looked for and confirmed in future studies.

The reason that no significant changes were observed in FEV 1 and FVC might be explained by the fact that FEV 1 and FVC are not very sensitive predictors of small airway disease, and the number of enrolled patients might be too small to detect significant differences. Therefore we also recommend further investigations to confirm and elucidate these findings.

The significant correlation between the inflammation expressed as elevated values of CRP and the reduction in F 25-75 point to fact that the small airways are likely to be inflamed. Brugman and co-workers developed a rabbit model to identify mechanisms associated with lower airway changes in sinusitis. ${ }^{12}$ They suggest that drainage of material to the lower airway may contribute to changes in airway function such as changes in bronchial responsiveness, but whether it is mediators, cytokines, or other factors has not been established, nor has it been identified that inflammatory factors are generated in the sinuses and directly enter the lower airway. In some patients a condition characterised by chronic sinusitis and chronic pulmonary infection - the so-called sinobronchial syndrome (SBS) - is recognised. The possible pathogenesis of SBS might involve inherited predisposition and some deficiencies in the host defence of the respiratory system. ${ }^{13}$ Blomgren et $a{ }^{14}$ showed that a decrease in nasal PEF was associated with the diagnosis of acute maxillary sinusitis in adults in primary care, but no spirometry was performed. In contrast, viral respiratory infections are highly associated with both acute sinusitis and asthma in predisposed patients. ${ }^{15-17}$

Throughout the study, we chose not to take into account patients' intake of weak analgesics e.g. paracetamol and local decongestives, since these are sold over the counter in Denmark.

\section{Conclusion}

This study showed that acute rhinosinusitis is accompanied by a temporary but significant reduction in the pulmonary function variables $F_{25-75}$ and PEF, possibly caused by inflammation in the small airways or a reflex mechanism. Further investigations are recommended to confirm and elucidate this finding.

\section{Conflict of interest declaration \\ None declared}

\section{Funding}

Danish Practitioners' Foundation for Education and Development.

\section{References}

1. Fokkens $W$, Lund $V$, Bachert $C$, et al. EAACI Position Paper on Rhinosinusitis and Nasal Polyps Executive Summary. Allergy 2005;60(5):583-601. http://dx.doi.org/10.1111/j.1398-9995.2005.00830.x

2. Hansen JG, Schmidt $H$, Rosborg J, Lund E. Predicting acute maxillary sinusitis in a general practice population. BMJ 1995;311(6999):233-36.

3. Kim JS, Rubin BK. Nasal and sinus inflammation in chronic obstructive pulmonary disease. COPD 2007;4(2):163-66.

4. Bachert C, Patou J, Van Cauwenberge P. The role of sinus disease in asthma. Curr Opin Allergy Clin Immunol 2006;6(1):29-36. http://dx.doi.org/10.1097/01.all. 0000200504.54425.0e

5. Druce HM, Slavin RG. Sinusitis: a critical need for further study. J Allergy Clin Immunol 1991;88:675-7. http://dx.doi.org/10.1016/0091-6749(91)90161-G

6. Rachelefsky GS, Katz RM, Siegel SC. Chronic sinus disease with associated reactive airway disease in children. Pediatrics 1984;73:526-9.

Rossi OVJ, Pirilä T, Laitinen J, Huhti E. Sinus aspirates and radiographic abnormalities in severe attacks of asthma. Int Arch Allergy Immunol 1994; 103:209-13.

8. Lindbæk M, Hjortdahl P, Johnsen U L-H. Randomised, double blind, placebo controlled trial of penicillin $\mathrm{V}$ and amoxycillin in treatment of acute sinus infections in adults. BMJ 1996;313:325-9.

9. Hansen JG, Schmidt H, Grinsted P. Randomised, double blind, placebo controlled trial of penicillin $\mathrm{V}$ in the treatment of acute maxillary sinusitis in adults in general practice. Scand J Prim Health Care 2000;18:44-7

10. Siafakas NM, Vermeire P, Pride NB, et al. ERS Consensus Statement. Optimal assessment and management of chronic obstructive pulmonary disease (COPD). Eur Respir J 1995;8(8):1398-420

11. Danish Society of Respiratory Medicine. Spirometry - a recommendation (in Danish). Copenhagen: Danish Society of Respiratory Medicine, 1986

12. Brugman SM, Larsen GL, Henson PM, Honor S, Irvin CG. Increased lower airways responsiveness associated with sinusitis in a rabbit model. Am Rev Respir Dis 1993;147(2):314-20.

13. Sugiyama Y. Sinobronchial syndrome. Nippon Rinsho 1999;57(9):2119-22.

14. Blomgren K, Hytönen M, Pellinen J, Relander M, Pitkäranta A. Diagnostic accuracy of acute maxillary sinusitis in adults in primary care. Scand J Prim Health Care 2002;20(1):40-4.

15. Greenberger PA. Therapy in the management of the rhinitis/asthma complex. Allergy Asthma Proc 2003;24(6):403-07.

16. Osur SL. Viral respiratory infections in association with asthma and sinusitis: a review. Ann Allergy Asthma Immunol 2002;89(6):553-60.

17. Peters E, Scott $C$, Phillips CD, Wheatley LM, Platts-Mills TAE. Sinusitis and acute asthma in adults. Int Arch Allergy Immunol 1999;118(2-4):372-74. http://dx.doi.org/10.1159/000024140

\section{Available online at http://www.thepcrj.org}

